 \\ Омонимы как лингвистический ресурс для создания каламбура в рекламном тексте на китайском и русском языках
}

\author{
Ван Юйчжи
}

\begin{abstract}
Аннотация. Цель исследования - определить особенности омонимов в китайском и русском языках и функции их использования как вербального средства создания каламбура в китайском и русском рекламном тексте. В статье рассмотрены различные определения омонимов и принципы их классификации в китайском и русском языках, а также описаны и проанализированы примеры употребления различных типов омонимов в рекламе Китая и России. Научная новизна исследования состоит в том, что специфика использования омонимов для создания каламбура в китайском и русском рекламном тексте анализируется в сопоставительном аспекте. В результате доказано, что использование омонимов в рекламе обеих стран происходит по сходным механизмам и обеспечивает возможность эффективного воздействия на потребителей рекламируемой продукции. Кроме того, обнаружено, что наряду со сходствами существуют и некоторые различия как в лингвистическом определении омонимов, так и в аспекте их функционирования в рекламном тексте, которые объясняются особенностями двух языков.
\end{abstract}

\section{EN Homonyms as a Linguistic Resource for Creating Puns in an Advertising Text in the Chinese and Russian Languages}

\author{
Wang Yuzhi
}

\begin{abstract}
The aim of the study is to determine the features of homonyms in the Chinese and Russian languages and the functions of their use as a verbal means of creating puns in the Chinese and Russian advertising text. The article discusses various definitions of homonyms and the principles of their classification in the Chinese and Russian languages, as well as describes and analyses the examples of using various types of homonyms in advertising in China and Russia. The scientific originality of the research lies in the fact that the specificity of using homonyms to create puns in the Chinese and Russian advertising text is analysed in a comparative aspect. As a result, it has been proven that the use of homonyms in advertising in both countries follows similar mechanisms and provides an opportunity for effective impact on consumers of the advertised products. In addition, it has been found that along with similarities, there are some differences both in the linguistic definition of homonyms and in the aspect of their functioning in the advertising text, which are explained by the peculiarities of two languages.
\end{abstract}

\section{Введение}

Благодаря своему креативному потенциалу омонимия как одно из важных лингвистических явлений постоянно привлекает внимание исследователей в самых разных научных областях, в том числе языкознания, литературоведения, рекламы и т.д. Как отмечает известный учёный В. В. Виноградов, «проблеме омонимии придается очень большое значение в самых разнообразных лингвистических концепциях и в самых различных областях лингвистического исследования» (Виноградов, 1960, с. 3).

Следует отметить, что существуют заметные различия в определении и способах классификации омонимов в различных языках, принадлежащих разным языковым семьям, поэтому актуальность темы исследования обусловлена, во-первых, важностью выявления специфики функционирования омонимов в китайском и русском языках; во-вторых, востребованностью явления омонимии как одного из важных вербальных средств для создания каламбура в китайском и русском рекламном тексте.

Таким образом, в данной работе объектом исследования являются китайские и русские омонимы, а предметом - особенности их использования для создания каламбура в китайском и русском рекламном тексте. 
Для достижения указанной цели необходимо решить следующие задачи: рассмотреть определение омонимов в китайской и русской научных традициях; выявить разновидности омонимов в китайском и русском языках; провести анализ омонимов как важного средства воздействия в китайском и русском рекламном тексте.

В статье применяются следующие методы исследования: лексико-семантический и контекстуальный анализ, семантическая и прагматическая интерпретация компонентов текста и сопоставительный метод.

Материалом нашего исследования послужили рекламные тексты, которые размещаются в российском и китайском сегментах Интернета.

Теоретической базой исследования являются труды лингвистов по теоретическим проблемам омонимии в русском (Виноградов, 1960; 1975a; 1975b; 1977; Новиков, 1982; Шанский, 2009; Костомаров, 2015; Ручимская, 2016) и китайском языках (Чжан Юнянь, 1982; Ван Цинь, У Чжанькунь, 1983; Гэ Бэньи, 1985; Сунь Жуцзянь, 2003; У Цичжу, 2003; Чжоу Цумо, 2006), а также по исследованию каламбура (Приходько, 2008; Михеева, 2013; Амири, 2015).

Практическая значимость исследования заключается в том, что выводы данной работы можно использовать при обучении китайскому и русскому языкам, а также в практике преподавания спецкурсов по сопоставительному языкознанию и маркетинговой лингвистике.

\section{Основная часть}

Российский учёный В. В. Виноградов характеризует омонимию как «совпадение разных слов или разных форм по своему внешнему звуковому облику» (Виноградов, 1975а, с. 13). Л. А. Новиков, в свою очередь, рассматривает лексическую омонимию как «семантическое отношение внутренне несвязанных значений, выражаемых формально сходными знаками и различающихся в тексте благодаря разным контекстуальным окружениям» (Новиков, 1982, с. 209).

В определении омонимов среди российских лингвистов в основном существуют два разных мнения: такие учёные, как В. В. Виноградов и Л. А. Булаховский, понимают омонимы как слова, которые одинаковы по звуковой форме и различаются прямыми нормативными значениями (Виноградов, 1977, с. 288-294; Булаховский, 1954, с. 53). Другие учёные, например Н. М. Шанский (2009, с. 52), считают, что омонимы должны совпадать не только по звуковым, но и графическим формам.

Академик В. В. Виноградов (1975b, с. 295) говорит о существовании узкого и широкого подходов к классификации омонимов. К омонимам в узком смысле относятся лексические омонимы, под которыми надо понимать слова, одинаковые по произношению и написанию, но различающиеся по значению. Эти омонимы в целом разделяются на две группы: 1) полные лексические омонимы (предложение - 'рекомендация' и предложение 'грамматическая категория синтаксиса'; предлог - 'служебная часть речи’ и предлог - ‘повод’, бор - ‘лес с преобладанием одного вида хвойных деревьев’ и бор - ‘химический элемент’ и т.д.); 2) неполные лексические омонимы (мир - 'состояние спокойствия’ и мир - 'планета Земля’; лук - 'вид оружия для стрельбы стрелами' и лук - ‘вид луковичных растений’ и т.д.).

К омонимам в широком смысле помимо лексических омонимов относятся и омофоны (луг - 'земля, покрытая травой’ и лук - ‘оружие’, бал - ‘вечер с танцами’ и балл - ‘единица количественной оценки’ и т.д.), омоформы (стих - форма единственного числа мужского рода прошедшего времени глагола стихнуть и стих - 'строка поэтического произведения', трём - форма первого лица множественного числа настоящего времени глагола тереть и трём - дательный падеж числительного три и т.д.) и омографы (орга́н - 'музыкальный инструмент' и о́рган - 'часть живого организма', ámлас - 'сборник географической справочной информации’ и атла́c - ‘плотная ткань' и т.д.), которые, с точки зрения В. В. Виноградова (1975b, с. 295), являются смежными с лексической омонимией явлениями.

В китайском языке также существует долгая традиция изучения омонимов. Мнения исследователей по отдельным вопросам омонимии несколько расходятся. Такие учёные, как Чжоу Цумо (2006, с. 31) и Гэ Бэньи $(1985$, с. 123$)$ считают, что омонимы - это слова, одинаковые по произношению, но полностью различающиеся по значению. Чжан Юнянь (1982, с. 115), Сунь Жуцзянь (2003, с. 194) и ряд других учёных считают, что разница значений не является обязательным условием для омонимов. Кроме того, существует ещё одна точка зрения: китайские лингвисты У Цичжу (2003, с. 217), Ван Цинь и У Чжанькунь (1983, с. 153) рассматривают тождественное произношение как единственное условие омонимов, не учитывая при этом их семантические отношения.

В китайском языке в основном выделяются три принципа классификации омонимов:

1. Классификация по количеству слогов омонимов. По этому признаку можно выделить односложные, двусложные и многосложные омонимы, к которым относятся полные лексические омонимы и омофоны. Например, односложные омонимы: 名 [мин] - ‘имя’ и 明 [мин] - ‘ясный’, 月 [юэ] - ‘месяц’ и 越 [юэ] - ‘пересекать’; двухсложные омонимы: 大家 [да цзя] - ‘все’ и 大家 [да цзя] - ‘известный человек’, 深滟 [шэнь юань] ‘омут’ и 伸冤 [шэнь юань] - ‘жаловаться’; многосложные омонимы: 中国画 [чжун го хуа] - ‘китайская национальная живопись' и 中国话 [чжун го хуа] - 'китайский язык’.

2. Классификация по написанию омонимов. По данному признаку выделяются две разновидности: во-первых, омонимы, которые имеют одинаковое произношение и написание, как лексические омонимы в русском языке, например: 杜鹃 [ду цзюань] - ‘цветы’ и 杜鹃 [ду цзюань] - ‘птицы’; во-вторых, это омонимы, которые совпадают по произношению, но различаются по написанию, то есть омофоны. Например, 公式 [гун ши] ‘формула’ - 公示 [гун ши] 'объявление’. 
3. Классификация по частеречной принадлежности. Здесь выделяются две разновидности: во-первых, омонимы, принадлежащие одной и той же части речи (например, глагол 霸占 [ба чжань] - 'захватить силой' и глагол 罢战 [ба чжань] - ‘прекратить войну'); во-вторых, омонимы, принадлежащие разным частям речи (например, глагол 办事 [бань ши] 'заниматься делами’ - имя существительное 半世 [полжизни]).

Рассмотрим использование омонимов как средства создания каламбура в текстах китайской и российской рекламы. Под каламбуром следует понимать любую языковую игру, которая производит одновременное параллельное двойственное восприятие ассоциативно связанных значений в сознании адресанта и адресата и несоответствие плана содержания и плана выражения с целью образования комического эффекта (Приходько, 2008, с. 142). В рекламном дискурсе омонимы часто рассматриваются как лингвистический ресурс для создания каламбура (Михеева, 2013, с. 8; Амири, 2015, с. 110). Такой приём нередко наблюдается в китайской и российской рекламе.

Рассмотрим случаи использования омонимов в русской рекламе.

1. Текст рекламы сока «Я»: «Где наслаждение, там $\boldsymbol{Я » .}$

В этом тексте наблюдаются омонимы $я$ - личное местоимение первого лица, которое обозначает говорящего (Толковый словарь русского языка, 2006, с. 915), и $Я$ - имя собственное, которое используется в качестве номинации рекламируемого сока. Использование личного местоимения в номинации обыгрывает букву я, что можно рассматривать как выразительное языковое средство.

2. Текст рекламы пива «Охота»: «Раннее утро. Выходим в море. Но на берег мы всегда сходим с охотой. Охота - крепость и выдержка. За эти качества Охота признана лучшим пивом года».

В этом рекламном тексте наблюдаются омонимы: 1) охота - 'стремление, желание' (Толковый словарь русского языка, 2006, с. 486) и Охота - название рекламируемого пива; 2) крепость - ‘физическая сила’ и крепость - 'насыщенность (алкоголя)' (с. 305); 3) выдержка - 'долгим хранением доведение до высокого качества' и выдержка - 'самообладание' (с. 111). Кроме того, в данном контексте использовано омонимичное словосочетание $c$ охотой: оно выступает не только в значении наречия охотно, но и в качестве имени собственного Охотой, являющегося наименованием предмета обладания (пива «Охота»). Адресант с помощью омонимов не только подчёркивает качество рекламируемого пива, но и придаёт этому продукту вымышленное символическое значение, позволяя потребителю связывать пиво «Охота» с мечтой, силой и самообладанием. Такая символизация пива в рекламе помогает эффективно воздействовать на мужскую часть целевой аудитории, используя гендерные стереотипы.

3. Текст рекламы мороженого «Оазис»: «Найди свой Оазис!».

В этом рекламном тексте наблюдаются полные омонимы оазис - 'место в пустыне или полупустыне, где есть растительность и вода’ (Толковый словарь русского языка, 2006, с. 424), и Оазис - название рекламируемого мороженого. Мороженое всегда рассматривается как один из популярных пищевых продуктов для облегчения летней жары, а оазис - это место для спасения от жары в пустыне. В результате использования данных омонимов наименование продукта вызывает у потребителя положительный эмоциональноокрашенный ассоциативный ряд.

4. Текст рекламы конфет «Скитлс»: «Ищи радугу. Попробуй радугу».

В этом рекламном тексте наблюдается лексическая омонимия: слово радуга, используется как в прямом значении 'разноцветная дуга на небесном своде, образующаяся вследствие преломления солнечных лучей в дождевых каплях' (Толковый словарь русского языка, 2006, с. 640), так и в качестве наименования разноцветных, похожих на радугу конфет «Скитлс». Использование омонимов в данном тексте, с одной стороны, подчёркивает специфику продвигаемого продукта, с другой стороны, позволяет целевой аудитории ассоциировать рекламируемые конфеты с радостью и «разноцветной» жизнью.

5. Текст рекламы шоколадных батончиков “Kit Kat”: «Ecmb nepepыв - ecmb Kit Kat».

В данном рекламном тексте наблюдаются омоформы: есть - форма инфинитива глагола в значении 'принимать пищу’ и есть - форма единственного числа, настоящего времени глагола быть в значении 'существовать’ (Толковый словарь русского языка, 2006, с. 188). Трансформация подразумеваемых омонимов как метод реализации манипулирования обыгрывает такую коммуникативную ситуацию: когда наступает перерыв, нужно покупать и есть Kit Kat для энергии и бодрости - это быстро и удобно.

6. Текст рекламы кваса «Никола»: «Нет коланизации - квас: здоровье нации».

В данном рекламном тексте наблюдаются омофоны коланизация и колонизация. Слово коланизация образуется по аналогии с существительным колонизация в соответствии со словообразовательным образцом американизировать $\rightarrow$ американизация (то есть внедрение в массовое сознание американских традиций) (Омельяненко, 2019, с. 138) и обозначает доминирующее место американского напитка Кола на рынке. По этой причине, адресант выражает свою оппозицию против колы и продвигает русский национальный напиток квас, воздействуя на патриотические чувства целевой аудитории.

Рассмотрим случаи использования омонимов в китайской рекламе.

1. Текст рекламы молока 《伊利》 [И Ли]: 《新年健康升级, 一起“家”满活力!» [В новом году здоровье перейдёm на новый уровень, все семьи полны жизненной силой!] (здесь и далее перевод выполнен автором статьи. - В. Ю.).

В данном рекламном тексте наблюдаются омофоны 家 и 加, потому что китайские слова 家 - 'семья’ (Словарь современного китайского языка, 2016, с. 621) и 加 - 'наполнить, добавить' (с. 623) имеют одинаковое произношение [jiā]. Следовательно, последняя фраза 《一起“家”满活力!» может иметь следующие варианты перевода: 1) все семьи полны жизненной силой; 2) вместе наполним себя жизненной силой; 3) вместе наполним семью жизненной силой. В результате использования омонимии рекламный текст не только сообщает 
о полезности рекламируемого продукта (молока), но и, обращаясь к семейным ценностям, оказывает эмоциональное воздействие на целевую аудиторию.

2. Текст рекламы подсолнечного масла «福临门》[Счастье у порога]: 《营养家, 健康加! » [Cпещиалист по питанию, здоровье добавлено!].

В данном рекламном тексте адресант использует омофоны 家 и 加: слово 家 в китайском языке имеет два значения: ‘семья’ и ‘специалист’, а слово 加 - ‘добавить’ (Словарь современного китайского языка, 2016, с. 621) звучит как слово 家 - ‘специалист’ (с. 623), поэтому данный рекламный текст имеет два значения: 1) ‘подсолнечное масло «福临门» [Счастье у порога] является специалистом по питанию и может улучшать здоровое состояние’; 2) ‘подсолнечное масло «福临门》 [Счастье у порога] - это и специалист по питанию, и специалист по здоровью’. Кроме того, благодаря симметричному построению текста, омофоны 家 и 加 позволяют использовать рифмы и повтор как фонетические выразительные средства.

3. Текст рекламы газированного напитка 《Спрайт»: 《我由我主张, 渴自由释放, 活只此一场, 梦肆意生长。透 心凉, 渴释放。» [Я выступаю за себя, жажду освобождения, живу только раз, мечтаю, как хочется. Леденящий холод, освобождение от жажды].

В рекламном тексте наблюдаются омофоны 渴 и 可. В китайском языке слово 渴имеет несколько значений: 1) ‘потребность пить’; 2) ‘стремление к чему-либо’; 3) ‘хотеть пить’; 4) ‘страстно хотеть чего-либо’ (Словарь современного китайского языка, 2016, с. 739). Кроме того, оно по произношению совпадает со словом 可 ‘мочь; можно' (с. 737). В силу этого в данном рекламном тексте адресат может ассоциировать фразу «渴释放» с такими значениями: 1) ‘жаждать освобождения’; 2) ‘могу освободиться’; 3) ‘освобождение от жажды’. Следовательно, использование омофонов 渴 и 可позволяет не только сообщить потребителю о назначении рекламируемого напитка, но и придать тексту большую экспрессивность. Помимо этого, многозначность слова 渴 в китайском языке позволяет построить многозначное параллельное предложение.

4. Текст рекламы продуктов питания компании «旺旺» [Ван Ван]: 《大礼, 有旺相伴。»[Большой подарок, который сопровождается благоденствием].

В данном контексте наблюдаются лексические омонимы, потому что китайское слово 旺, обозначающее ‘благоденствие’ (Словарь современного китайского языка, 2016, с. 1356), в данном рекламном тексте употребляется ещё и как наименование бренда продуктов питания - «旺旺» [Ван Ван], которое образовано с помощью повтора слова 旺. Следовательно, рекламодатель не только сообщает, что продукты питания компании можно рассматривать как удачный, правильный выбор подарка, но и убеждает потребителя, что рекламируемые продукты символизируют благоденствие.

5. Текст рекламы газированного напитка «Пепси»: «有百事, 聚爽!» [Пепси есть, это приятно для компании!].

В данном контексте наблюдаются омофоны 聚 - 'собрание' (Словарь современного китайского языка, 2016, с. 709) и 巨 - 'очень' (с. 706). Следовательно, рекламный текст может иметь два значения: 1) 'Пепси есть, это приятно для собрания (компании)'; 2) 'Пепси есть, это очень приятно’. Использование омофонов как выразительного средства позволяет адресанту продемонстрировать важность наличия рекламируемого напитка для собрания (компании) и в то же время оказать положительное эмоциональное воздействие на потребителя.

\section{Заключение}

Таким образом, на основе проведённого исследования можно сделать следующие выводы:

1. В китайском и русском языкознании наблюдается сходство в понимании омонимов, что проявляется в подчёркивании тождественности их произношения. Однако существуют и заметные различия в определении омонимов в китайском и русском языках. Для российских учёных различие подходов к пониманию омонимов связано с необходимостью одинаковой графической формы, а китайские учёные не рассматривают это как обязательный фактор. В отличие от российских исследователей, китайские учёные уделяют больше внимания обсуждению семантических отношений омонимов.

2. В китайском и русском языках разновидности омонимов частично совпадают, что проявляется в наличии омофонов и полных лексических омонимов в обоих языках. Однако в китайском языке, в отличие от русского, отсутствуют неполные лексические омонимы, омографы и омоформы. Отсутствие неполных лексических омонимов и омоформ объясняется тем, что китайский язык относится к числу корнеизолирующих языков, не имеющих грамматических изменений. Отсутствие омографов связывается с тем, что китайские исследователи, в отличие от российских учёных, не выделяют широкий и узкий подходы к определению омонимов, следовательно, совпадение по звуковой форме рассматривается как необходимое условие для омонимов в китайском языке.

3. Омонимы активно используются в китайской и русской рекламе как средство создания каламбура, применение данного приёма для воздействия на целевую аудиторию имеет несколько преимуществ. Во-первых, использование омонимии позволяет адресантам создавать комический эффект в рекламе. Во-вторых, омонимы позволяют рекламодателям придавать рекламному тексту дополнительные значения, тем самым усиливая экспрессивность вербальной части рекламы. С помощью омонимов адресант может не только подчеркнуть специфику рекламируемых продуктов, но и вызвать определённый ассоциативный ряд, который производит сильное впечатление на адресата, помогая закрепить в его сознании информацию о рекламируемом объекте.

4. Наряду со сходствами существуют и различия в применении омонимов как выразительного средства в текстах российской и китайской рекламы. В русских рекламных текстах намного чаще наблюдается использование 
лексических омонимов - это объясняется тем, что в русском языке в лексему входят все значения того или иного слова. Типичный приём в русской рекламе - омонимия названий брендов. В китайском языке слог может соответствовать нескольким иероглифам, поэтому использование омофонов может позволять китайской аудитории ассоциировать написанное слово с другими словами, одинаковыми по произношению.

Перспективы дальнейшего исследования заключаются в необходимости более подробного изучения и описания особенностей и функций конкретных разновидностей китайских и русских омонимов в рекламе Китая и России разных тематических разновидностей.

\section{Источники | References}

1. Амири Л. П. Омонимия как один из полюсов на шкале неоднозначности языковой игры в рекламе // Вестник славянских культур. 2015. № 1 .

2. Булаховский Л. А. Введение в языкознание. М.: Учпедгиз, 1954.

3. Виноградов В. В. О грамматической омонимии в современном русском языке // Избранные труды. Исследования по русской грамматике. М.: Наука, 1975а.

4. Виноградов В. В. Об омонимии в русской лексикографической традиции // Избранные труды. Лексикология и лексикография. М.: Наука, 1977.

5. Виноградов В. В. Об омонимии и смежных явлениях // Вопросы языкознания. 1960. № 5.

6. Виноградов В. В. Об омонимии и смежных явлениях // Избранные труды. Исследования по русской грамматике. М.: Наука, $1975 \mathrm{~b}$.

7. Костомаров В. Г. Современный русский литературный язык. М.: Юрайт, 2015.

8. Михеева Е. С. Стилистический прием полисемантики в текстах СМИ (на материале русскоязычных газетных заголовков и рекламных слоганов): автореф. дисс. ... к. филол. н. М., 2013.

9. Новиков Л. А. Семантика русского языка. М.: Высшая школа, 1982.

10. Омельяненко В. А. Мультимодальные способы репрезентации имиджа России в текстах национальноориентированной рекламы: дисс. ... к. филол. н. М., 2019.

11. Приходько В. К. Выразительные средства языка. М.: Издательский центр «Академия», 2008.

12. Ручимская Е. М. О лексической омонимии // Русская речь. 2016. № 1.

13. Толковый словарь русского языка: 80000 слов и фразеологических выражений / ИРЯ РАН; под ред. С. И. Ожегова и Н. Ю. Шведовой. М.: А ТЕМП, 2006.

14. Шанский Н. М. Лексикология современного русского языка: учебное пособие. М.: Книжный дом «ЛИБРОKOM», 2009.

15. 葛本仪. 汉语词汇研究. 济南: 山东教育出版社, 1985 (Гэ Бэньи. Исследование о китайской лексике. Пекин: Преподавание и исследование иностранных языков, 1985).

16. 现代汉语词典 (第7版). 中国社会科学院语言研究所词典编辑室. 北京: 商务印书馆, 2016 (Словарь современного китайского языка / под ред. отдела по словарям Института лингвистики академии общественных наук КНР. Изд-е 7-е. Пекин: Коммерческое издательство, 2016).

17. 孙汝建. 现代汉语. 南京:南京大学出版社, 2003. (Сунь Жуцзянь. Современный китайский язык. Нанкин: Издательство Нанкинского университета, 2003).

18. 武占坤 王勤. 现代汉语词汇概要. 呼和浩特: 内蒙古人民出版社, 1983 (У Чжанькунь, Ван Цинь. Основы лексики современного китайского языка. Хух-Хото: Народ Внутренней Монголии, 1983).

19. 吴启主. 现代汉语教程. 长沙:湖南师范大学出版社, 2003 (У Цичжу. Курсы современного китайского языка. Чанша: Издательство Хунаньского педагогического университета, 2003).

20. 张永言. 词汇学简论. 武汉:华中工学院出版社, 1982 (Чжан Юнянь. Очерки о лексикологии. Ухань: Издательство Центрального китайского технологического института, 1982).

21. 周祖谟. 汉语词汇讲话. 北京:外语教学与研究出版社, 2006 (Чжоу Цумо. Речь о лексике в китайском языке. Пекин: Преподавание и исследование иностранных языков, 2006).

\section{Информация об авторах | Author information}

RU Ван Юйчжи ${ }^{1}$

${ }^{1}$ Российский университет дружбы народов, г. Москва

EN Wang Yuzhi ${ }^{1}$

${ }^{1}$ Peoples' Friendship University of Russia, Moscow

${ }^{1}$ van_yu@pfur.ru

\section{Информация о статье | About this article}

Дата поступления рукописи (received): 09.10.2021; опубликовано (published): 30.11.2021.

Ключевые слова (keywords): омонимы; китайский язык; русский язык; сопоставительный анализ; рекламный текст; homonyms; Chinese language; Russian language; comparative analysis; advertising text. 